Quality of lettuce packed in crates

\title{
1 Early Postharvest Time Period Affects Quality of Butterhead Lettuce Packed in \\ 2 Crates
}

3

4 M.V. Agüero, G.E. Viacava, A.G. Ponce, and S I. Roura

5

6 Grupo de Investigación en Ingeniería en Alimentos. Facultad de Ingeniería. Universidad Nacional

7 de Mar del Plata. Juan B. Justo 4302. Zip code: 7600. Mar del Plata, Argentina and Consejo

$8 \quad$ Nacional de Investigaciones Científicas y Técnicas

9

10 Address correspondence to: M.V. Agüero at the above address. E-mail: mvaguero@fi.mdp.edu.ar

12 Acknowledgements

13 This work was supported by Consejo Nacional de Investigaciones Científicas y Técnicas, Agencia 14 Nacional de Promoción Científica y Tecnológica (Secyt) and Universidad Nacional de Mar del 15 Plata.

17 The period between when butterhead lettuce (Lactuca sativa var. L) heads are harvested and stored 18 in cold rooms can be up to 24 hrs. During this period, environmental conditions are uncontrolled, 19 and heads could undergo deterioration that has not been previously quantified. Quality changes of 20 lettuce heads packed in crates, and exposed to optimal or sub-optimal conditions, during the $24 \mathrm{hrs}$ 21 after harvest were evaluated. Effects of placement within crates (lower, middle and upper layer) 22 was assessed. Proximity of heads within crates created a barrier to transfer of heat and humidity.

23 This resulted in negative responses for plants under optimal conditions because there was a delay in 24 temperature reduction and a deterioration in quality. At sub-optimal conditions the response was 25 positive because respiration and transpiration allowed development of a saturated environment 26 around heads delaying loss of quality. This effect was most obvious in heads from middle and 
Quality of lettuce packed in crates

27 lower layers which present the highest overall visual quality and water content. Use of crates caused

extensive mechanical damage on heads, making it necessary to discard outer leaves leading to 10 and $35 \%$ weight losses under optimal and sub-optimal conditions, respectively. Initial quality rapidly decreases in the first day after harvest. It is necessary that technologies be upgraded to reduce quality and economic losses.

Keywords: Lactuca sativa, Argentina, discards, optimal conditions, quality change, sub-optimal conditions, weight loss

Butterhead lettuce (Lactuca sativa var. Lores) is one of the most consumed leafy vegetables in the world. In many European countries and North America, vacuum cooling is the standard treatment used to maintain head quality (Mc Donald and Sun, 2000). This cooling method allows a quick removal of field heat by reducing tissue temperature from 25 to $1^{\circ} \mathrm{C}$ in $30 \mathrm{~min}$. Beneficial effects of vacuum cooling on shelf-life of iceberg lettuce (Lactuca sativa L.) have been studied (He and $\mathrm{Li}$, 2008; Ozturk and Ozturk, 2009). However, this procedure does not constitute a common practice for butterhead lettuce in Argentina and other developing countries, where lettuce heads are packed in crates immediatly after harvest and transported to distribution centers without any conditioning. The period between harvest and storage in a cold room is about $24 \mathrm{hrs}$ including time in the field, transportation and delay at the distribution center. This period is known as early postharvest, and the importance of these first hours after harvest on vegetable shelf-life is known (Agüero et al., 2009; Moreira et al., 2006; Watada et al., 1996).

The environment surrounding fresh vegetables has a significant effect on shelf life of vegetables (Paull, 1999). Temperature $(\mathrm{T})$ and relative humidity $(\mathrm{RH})$ of air near the produce are main factors involved in postharvest preservation as they affect organoleptic quality (Nunes et al., 2009), which impacts consumer acceptability. The temperature effect on vegetable quality is well known (Paull, 1999). Temperature reduction is the simplest way to delay deterioration (through 
Quality of lettuce packed in crates

53

54

55

56

decreases in metabolic reaction rates) and retain fresh product appearance (Nunes et al., 2009; Paull, 1999). Relative humidity also directly impacts produce quality during storage (Nguyen et al., 2007). Water loss from vegetables is driven by the water gradient between the internal vegetable space and the surrounding air. Assuming that air inside the vegetable tissue is saturated (Paull, 1999), the water vapor pressure deficit (WVPD; the difference between the actual vapor pressure and the saturation vapor pressure, Hertog et al., 2004), could be used to quantify the water gradient. When produce is exposed to high WVPD, water and weight losses, wilting, and other deleterious effects occur (Nguyen et al., 2007). As water loss is a superficial phenomenon (Mahajan et al., 2008), it is a serious problem for lettuce, and for all leafy vegetables, because they have a high surface to volume ratio.

Although use of wooden crates, without pre-cooling, is widespread and constitutes a general management practice between producers and distributors, there are few studies examining the impact of this type of handling on lettuce quality (Mondino et al., 2007). There is a worldwide tendency to revise the handling during commercialization of agri-food products (Ahumada and Villalobos, 2009). Quality changes occurring during distribution and sale of lettuce are potential areas for further research (Nunes et al., 2009).

The objective of the present work was to study effects of exposure of lettuce heads packed in wooden crates during the first $24 \mathrm{hrs}$ after harvest to environmental conditions on physiological, nutritional, microbiological, physicochemical and sensory quality indices. Effects of placement of lettuce head in the crate was assessed. Also, effects of crate storage was compared to uncrated lettuce heads.

\section{MATERIALS AND METHODS}

\section{Plant Material and Sample Preparation}

Heads of butterhead lettuce were grown in greenhouses in Sierra de los Padres, Mar del Plata, Argentina. Lettuce heads were harvested after reaching a marketable size (approx. 24-30 leaves per head) and immediately transported to the laboratory, where eight units were analyzed in the first 
Quality of lettuce packed in crates

hour after harvest to evaluate initial lettuce quality status. Other lettuce heads were individually weighed and placed in wooden crates following the protocol used in commercial practice. A first layer of six heads (lower layer) was placed at the bottom of the crate with the cut end upwards. An additional six heads, forming the middle layer, were placed above the first one following the same orientation. Finally, nine heads, with the same previous orientation, formed the upper layer (Fig. 1.). Two environmental chambers (SCT, Pharma, Buenos Aires, Argentina) were used to create the test conditions: one of was $0-2^{\circ} \mathrm{C}$ and $95-97 \%$ RH ( $a$ condition or optimal) and another was $20-$ $22^{\circ} \mathrm{C}$ and $60-62 \% \mathrm{RH}$ ( $b$ condition or sub-optimal). Temperature and $\mathrm{RH}$ were recorded in crates at lower, middle and upper layers to determine the evolution of these variables in the air around lettuce heads. Two data acquisition systems were used: Testostor 175-H1 (TESTO, Buenos Aires, Argentina) and EASYLOG (Lascar Electronics, Buenos Aires, Argentina). Two crates were exposed to optimal conditions, and two used for sub-optimal conditions during $24 \mathrm{hrs}$, the period designated as early postharvest. After this period lettuce heads were removed from crates and individually weighed. Lettuce heads from each layer were used to evaluate two simultaneous effects: environmental conditions during the early postharvest period (optimal or sub-optimal), and placement of lettuce heads within crates.

An additional 6 heads were not crated and exposed to each environmental condition to evaluate quality changes for comparison to crated heads. The experiment was replicated three times.

\section{Weight loss}

Weight loss was determined in all lettuce heads after the early postharvest period. Each head was weighed after being harvested when it arrived at the laboratory $\left(\mathrm{W}_{0}\right)$, and then, after $24 \mathrm{hrs}\left(\mathrm{W}_{24}\right)$. Weight loss (WL) of each individual head was calculated (Agüero et al., 2011c).

After $\mathrm{W}_{24}$ data were obtained, broken and/or deteriorated, leaves were removed from lettuce heads and an additional weight taken ( $\mathrm{W}_{24 \mathrm{w}}$, weight after waste disposal) and weight loss after discards made $\left(\mathrm{WL}_{\mathrm{d}}\right)$ calculated considering this new weight. 
Quality of lettuce packed in crates

104

105

106

107

108

109

110

111

112

114

115

116

117

118

119

120

121

122

123

124

125

126

127

128

The WL and $\mathrm{WL}_{\mathrm{d}}$ were expressed as percent with respect to fresh initial weight. WL and $\mathrm{WL}_{\mathrm{d}}$ mean values were calculated for each layer. Mean values were also calculated for individually exposed lettuce heads.

\section{Quality indices}

Head lettuce quality was evaluated with the indices: physiological [water status: water content (WC), relative water content (RWC), free water (FW), bound water (BW) and free water to total water ratio $(\mathrm{FW} / \mathrm{TW})]$; microbiological (mesophilic bacteria count, $\mathrm{MBC}$ ); nutritional (reduced ascorbic acid content, AA); physicochemical (total chlorophyll content, TC), and sensory (overall visual quality, OVQ).

Three heads from each layer were used to evaluate physiological indices; and three heads were assigned to nutritional, microbiological, physicochemical and sensory indices. For uncrated exposed lettuce heads, the same number of units were used for determination of quality indices.

To determine plant water status, all leaves of each head were used as described by Viacava et al. (2011). Briefly, two rectangles $\left(15 \mathrm{~cm}^{2}\right)$ were cut from each leaf using a stainless steel cutter. The first rectangle, cut from the central apical area, was used for relative water content (RWC) and water content (WC) determinations. The other rectangle was cut $1 \mathrm{~cm}$ below the first, avoiding the midrib, and used for free water (FW), bound water (BW) and the relation between free and total water (FW/TW) determinations.

For RWC and WC, each rectangle from each leaf was weighed individually to obtain fresh mass (FM). Each rectangle was then placed in a humidified chamber consisting of a $10 \mathrm{~L}$ plastic box containing $5 \mathrm{~L}$ of distilled water and provided with a plastic hermetic cover to prevent moisture exchange. Rectangles were maintained for $20 \mathrm{hr}$ at $4^{\circ} \mathrm{C}$ in darkness. Next, rectangles were individually blotted with absorbent tissue paper and weighed to obtain turgid mass (TM). Finally, rectangles were dried for $24 \mathrm{hr}$ at $80^{\circ} \mathrm{C}$ in a forced air oven to determine dried mass (DM). Values of FM, TM, and DM were used to calculate RWC and WC (Viacava et al., 2011). After RWC and 
Quality of lettuce packed in crates

129 WC were determined, percentage change in respect to values at harvest were calculated. RWC and

$130 \mathrm{WC}$ are $\%$ of change after the $24 \mathrm{hr}$ period in respect to values at harvest.

131

132

133

The other rectangles obtained from leaves were weighed to obtain fresh mass (FM), and placed in $15 \mathrm{~mL}$ Falcon tubes for freezing in liquid nitrogen. Next, the rectangles were thawed; the leaf tissue spread out and air-dried on a table for $30 \mathrm{~min}$, weighed to obtain air dry value (AD), oven-dried for $24 \mathrm{hr}$ at $80^{\circ} \mathrm{C}$, and weighed (DM). Values of $\mathrm{FM}, \mathrm{AD}$, and $\mathrm{DM}$ were used to calculate total water (TW), free water (FW), and bound water (BW) per unit of dried mass (Viacava et al., 2011).

Data were pooled and the mean value obtained for each lettuce head, and for each layer of the crate (lower, middle and upper). The FW/TW values were calculated as the relation between these two indices. Once FW, BW and FW/TW were determined, percentage change with respect to values found at harvest were calculated. The indices are \% change after $24 \mathrm{hrs}$ with respect to values found at harvest.

To evaluate other quality indices, three lettuce heads where assessed by a panel for organoleptic quality, and the heads cut transversally in $2 \mathrm{~cm}$ portions and mixed, taking 2 samples from each lettuce head.

Total chlorophyll content (TC) was determined using the methodology of Moreira et al. (2005). Briefly, lettuce portions were homogenized with a commercial blender (Multiquick, MR 5550 CA Braun, Espanola S.A., Barcelona, Spain), and two samples (1 g each) taken from each homogenate. Each sample was homogenized with $19 \mathrm{~mL}$ of a cold 18:1 propanone:ammonium hydroxide solution $\left(0.1 \mathrm{~mol} \mathrm{~L}^{-1}\right)$. The homogenate was filtered through sintered glass and water removed from the filtrate with anhydrous sodium sulfate. Absorbance of the filtrate at 660.0 and $642.5 \mathrm{~nm}$ was with a UV 1601 PC UV-visible spectrophotometer (Shimadzu Corporation, Tokyo, Japan). Total Chlorophyll Concentration (CC) was calculated as:

$$
C C\left(m g \cdot L^{-1}\right)=7.12 \cdot A_{660}+16.8 \cdot A_{642.5}
$$


Quality of lettuce packed in crates

154

155

156

158

159

160

161

162

163

164

165

166

167

168

169

170

171

172

173

174

175

176

177

178

where $\mathrm{A}_{660}$ and $\mathrm{A}_{642.5}$ are absorbances at the corresponding wavelengths. After TC was determined, percent change with respect to values found at harvest were calculated. TC is $\%$ of change after the $24 \mathrm{hrs}$ in respect to values found at harvest.

Reduced ascorbic acid content was determined following Roura et al. (2001). Briefly, $20 \mathrm{~g}$ lettuce portions were extracted with $100 \mathrm{~mL}$ metaphosphoric acid solution $\left(60 \mathrm{~g}^{\mathrm{kg}} \mathrm{kg}^{-1}\right)$ for $3 \mathrm{~min}$ using a commercial blender (Multiquick, MR 5550 CA Braun, Espanola S.A., Barcelona, Spain) with an homogenizer speed of 3500 to $7000 \mathrm{rpm}$. The homogenate was made up to $250 \mathrm{~mL}$ with 30 $\mathrm{g} \cdot \mathrm{kg}^{-1}$ metaphosphoric acid and filtered through Whatman No. 42 filter paper. Temperature during ascorbic acid extraction was maintained at $0^{\circ} \mathrm{C}$. Three aliquots $(5 \mathrm{~mL}$ each) of filtrates were titrated with 2,6- dichloroindophenol. Ascorbic acid content was calculated as $\mathrm{mg} / 100 \mathrm{~g}$ of fresh mass. After AA was determined, percentage of change in respect to values found at harvest were calculated. AA is $\%$ of change after the $24 \mathrm{hrs}$ in respect to values found at harvest.

Mesophilic bacteria counts (MBC) were evaluated with the methodology of Ponce et al. (2002). Ten-g of lettuce portions were macerated in a buffer solution $\left(\mathrm{PO}_{4} \mathrm{~K}_{3}, \mathrm{pH}\right.$ 7.2). Enumeration of mesophilic bacteria was with plate count agar (PCA) incubated at $32-35^{\circ} \mathrm{C}$ for $48-72 \mathrm{hr}$. After MBC was determined, the value $(\mathrm{N})$ was related to that found at harvest $\left(\mathrm{N}_{0}\right)$ and transformed using the $\log$ function; $M B C$ is $\log \left(\mathrm{N} / \mathrm{N}_{0}\right)$.

Overall visual quality was evaluated by a sensory panel following Agüero et al. (2011a). Quality parameters as color (shade and uniformity), brightness, crispness, wilting, bacterial decay and physiological disorders (mainly midrib and edge browning of lettuce heads) were analyzed and scored with a 9 point scale with 9: excellent, 7: good, 5: fair (accept limit), 3: poor and 1: extremely poor. Average of indices was used as an estimation of overall visual quality (OVQ). Evaluations were carried out immediately after removal from storage. A panel comprised by 9 trained judges, aged 30-55 years, all members of the Food Engineering Group, and with sensory evaluation experience in leafy vegetables, was responsible for sensory evaluations. Coded (3 digit) samples 
Quality of lettuce packed in crates

179

180

181

182

183

were randomly presented to judges who made independent evaluations. Mean values obtained for each plant were used to calculate the mean value in crate layers.

\section{Statistical analysis}

Means were separated with LSMEAN (mean obtained with Least Square method) together with standard deviations (Kuehl, 2001). Data were analyzed using SAS (ver. 9.0; SAS Institute, 2002). The General Linear Model procedure was used to carry out the ANOVA.

A statistical model was used to evaluate effects of environmental conditions to which heads were exposed, and head placement within crates. variation sources used as factors of the two-way ANOVA were COND (optimal or sub-optimal), LAY (layer within the crate: lower, middle or upper) and COND $\times$ LAY interaction. A second statistical model was used to evaluate packaging effect (crate or none) and environmental conditions (optimal or sub-optimal). For this purpose, a two-way ANOVA was applied with the factors PACK, COND and PACK $\times$ COND. Data used for this analysis corresponded to mean values of lettuce heads from the same crate and to the mean of uncrated heads. For each model, differences among results obtained for different factor levels were evaluated with multiple comparisons Tukey-Kramer test. For both models, PROC UNIVARIATE was applied to validate ANOVA assumptions (Kuehl, 2001).

\section{RESULTS AND DISCUSSION}

\section{Weight loss}

The first analysis of variance (Table 1) yielded a significant interaction among LAY and COND. Regardless of placement within the crate and storage condition, crated lettuce heads had higher WL and $\mathrm{WL}_{\mathrm{d}}$ values when exposed to the highest temperature and lowest relative humidity ( $b$ condition) (Table 2). This could be attributed to water vapor pressure deficit (WVPD) of each storage condition; the driving force for water evaporation. This parameter was calculated as a function of $\mathrm{T}$ and RH (Guevara-Arauza et al., 2006), and was 73 times higher for sub-optimal condition (971.1 $\pm 74.6 \mathrm{~Pa})$ than for the optimal situation $(13.2 \pm 7.7 \mathrm{~Pa})$. 
Quality of lettuce packed in crates

204 When crates were exposed to optimal conditions, heads in the lower layer had the highest $205 \mathrm{WL}_{\mathrm{d}}$. Weight of heads above them, as well as the pressure exerted during packing, could be 206 responsible for the high $\mathrm{WL}_{\mathrm{d}}$. Use of wooden crates to transport lettuce from the field causes 207 mechanical damage in heads. The amount of damaged tissue depends on head size and care of 208 handling during packing. If lettuce heads are large, they will be tightly packed with 21 heads per 209 crate likely resulting in increased mechanical damage. Mondino et al. (2007), quantifying 210 postharvest losses of lettuce in the Rosario, Argentina, region found that $100 \%$ of producers used 211 wooden crates with a packing content with upper layers exceeding the physical limit of the wooden 212 crate (Fig. 1). This generates increases in weight loss due to discarded leaves as crates are emptied. 213 Heads from the middle layer of crates, which were exposed to sub-optimal conditions, had 214 less weight loss than those from upper and lower layers. This could be related to RH generated in 215 the wooden crate (Fig. 2B). Although the WVPD was high outside the crate, head proximity within 216 the crate generated increased RH of the air around heads. The wooden crate and the upper layer of 217 heads likely constituted a moisture barrier. Respiration and transpiration from heads generated 218 humidity that remained in the internal parts of the crate. Lettuce heads placed in the middle layer 219 had higher weight. Heads from the upper layer had a WL $62 \%$ higher than those from the middle 220 one. After discarding waste, $\mathrm{WL}_{\mathrm{d}}$ values from different layers were more similar, with values in the 221 upper layer being $13 \%$ higher than in the middle layer.

The second ANOVA (Table 3) yielded a significant interaction among PACK and COND. Despite being exposed to an environment with very low WVPD the heads packed in crates and exposed to optimal storage conditions had weight losses, while plants individually exposed to this condition did not (Table 4). Damage suffered by heads packed in crates led to higher weight losses 226 and waste compared with heads individually exposed to these conditions. Temperature and relative 227 humidity in the environment around packed lettuce were different from those in the environmental 228 chamber. Changes occurred in environmental variables in different layers inside crates during 24 hrs after harvest (Fig. 2). Lettuce heads from the upper layer reached the chamber temperature 
Quality of lettuce packed in crates

230 fastest; heads from the middle layer had the longer delay in reaching this temperature. These delays

231 could be responsible for higher weight loss detected in heads exposed to optimal conditions when

232 crated than when not crated. High temperature increases tissue respiration and transpiration.

233 Although RH was high in the chamber, high temperature implies high WVPD which favors water

234 and weight losses. In contrast, $\mathrm{WL}$ and $\mathrm{WL}_{\mathrm{d}}$ of uncrated heads to sub-optimal conditions were

235 higher than those for heads from crates exposed to the same condition, showing the protective effect

236 of packaging (Table 4 ). Average weight losses $\left(\mathrm{WL}_{\mathrm{d}}\right)$ of $34.69 \%$ for crates were mainly due to

237 mechanical damage and incipient dehydration in upper lettuce heads, while the $38.76 \%$ of $\mathrm{WL}_{\mathrm{d}}$ in

238 uncrated heads were principally due to wilting and dehydration.

239 Literature on the WL of lettuce heads during storage is lacking. In most works, different

240 combinations of $\mathrm{T}$ and $\mathrm{RH}$, and different lettuce varieties, were employed (Chandra et al., 2008;

241 Martínez-Romero et al., 2008; Martínez and Artés, 1999). Direct comparison with our results is

242 difficult. Lettuce variety is a key factor to be considered since each variety has particular

243 morphological properties. Iceberg lettuce has a high density, with small total surface exposed to the

244 environment. Butterhead lettuce has a more open structure, with greater exposed surface, favoring

245 water and weight losses.

246 Water status indices

247 Water status indices (RWC, WC, FW, BW and FW/TW) in crated and uncrated heads after 24 hrs

248 were affected by treatment (Fig. 3). Relative water content (RWC) is the relation between the 249 amount of water in tissue and the maximum amount of water that tissue can maintain (Agüero et al., 250 2011b). Head placement within the crate did affect RWC. Regardless of placement within the crate, 251 RWC decreased in all heads. However, RWC decreased $2.75 \pm 0.11$ and $4.35 \pm 0.40 \%$ in heads under 252 optimal and sub-optimal conditions. Reductions in RWC are usually associated with storage 253 environments with high WVPD. Decreases in RWC occurred in lettuce, and kiwi (Actinidia 254 chinensis Planch) and rambutan (Nephelium luppaceum L., cv. Jitlee) fruit during storage under low 255 RH (Agüero et al., 2011b; Burdon and Clark, 1996; Landrigan et al., 1996). Reduction in RWC 
Quality of lettuce packed in crates

256

257

258

259

260

261

262

263

264

265

decrements can be due to reductions in leaf fresh weight, and by increases in turgid weight when tissue deterioration is high. When plant tissue is exposed to a saturated environment damaged plant cells do not offer any resistance to water intake, resulting in a high turgid weight and a low RWC value (Agüero et al., 2008).

By analyzing RWC mean values for crated and uncrated heads RWC increased $(4.70 \pm 1.59 \%)$ in uncrated heads exposed to optimal conditions while a decrease $(2.75 \pm 0.11 \%)$ occurred in crated heads exposed to the same conditions. This RWC increase could be a response of lettuce tissue to high RH and low T, with minimum, or no differences in water vapor pressure between the head and the environment around it, causing cells to be saturated. Agüero et al. (2011b) found increases in RWC when butterhead lettuce was exposed to low WVPD. When sub-optimal conditions were used, uncrated lettuce heads had higher RWC decreases $(7.88 \pm 1.97 \%)$ than crated heads $(4.35 \pm 0.40 \%)$. This fact was probably related to development of a more saturated atmosphere surrounding heads within crates (Fig. 2B).

There were no changes in water content (WC) of crated lettuce exposed to optimal conditions for heads in layers. Lettuce heads from crates exposed to sub-optimal conditions exhibited decreased WC with the largest decline in upper layer heads, but no differences between middle and lower layers. There were no differences in WC of crated (Fig. 3C) and uncrated heads (Fig. 3D) when environmental conditions were optimal. Under sub-optimal conditions, upper-layer heads had the highest water loss. Other factors, in addition to a sub-optimal environment, could be responsible for increased water loss in the upper layer. The most significant could be excessive mechanical damage generated by packing 9 lettuce heads in the same layer. Water loss in vegetables depends on WVPD and is influenced by anatomical and morphological characteristics, tissue ripeness and damaged surfaces, among others and include temperature, relative humidity, and air movement (Ngure et al., 2009).

Crated lettuce heads (Fig. 3E) and uncrated heads (Fig. 3F) had decreased FW values at 24 hrs after harvest. No significant differences were observed in the FW behavior among layers in 
Quality of lettuce packed in crates

282

283

284

285

286

287

288

289

290

291

292

293

294

295

296

297

298

299

300

301

302

303

304

305

306

307

crates exposed to optimal conditions (mean decrease of $4.58 \pm 0.66 \%$ ). Heads from crates exposed to sub-optimal conditions had FW decreases as a function of placement within the crate with FW declines of $12.92 \pm 1.34,9.26 \pm 0.97$ and $3.68 \pm 1.57 \%$ for upper, middle and lower layers, respectively. The FW reductions were higher in uncrated than in crated heads. While a mean FW reduction of $8.62 \pm 4.66 \%$ occurred in crated heads exposed to sub-optimal conditions, a reduction of $51.8 \pm 4.93 \%$ was detected in uncrated heads exposed to the same conditions. These differences may be attributed to protection generated by the packaging system allowing development of a saturated atmosphere between heads inside the crates (Fig. 2B). Under optimal conditions, a smaller difference was detected between crated and uncrated lettuce heads with decreases of $11.79 \pm 1.84$ and $4.58 \pm 0.66 \%$, respectively.

Increments in BW occurred in crated heads (Fig. 3G) and uncrated heads (Fig. 3H) exposed to the same conditions. Regardless of placement within crates, similar BW increases occurred at optimal conditions (mean increase of $7.36 \pm 1.48 \%$ ). Differences occurred among layers in crates exposed to sub-optimal conditions $(23.40 \pm 0.65 \%$ for middle and lower layers without differences between them; and $12.78 \pm 0.78 \%$ for the upper layer). Uncrated heads exposed to optimal and suboptimal conditions had higher BW increments than heads in crates $(42.26 \pm 1.70$ and $20.68 \pm 1.10 \%$, respectively). In addition to the protective effect due to the packaging system, lower increases in crated heads under to sub-optimal conditions, could be due to the thermal profile developed inside the crate (Fig. 2A), with a gradual temperature reduction avoiding the rapid reduction that could increase retention of water (as BW).

The FW/TW decreases were detected in all lettuce heads whether crated or not, placement within the crate, and the storage condition (Fig. 2I, J). Plants from crates under optimal conditions had a reduction in the FW/TW values of $4.61 \pm 2.5 \%$, while heads from crates exposed to suboptimal conditions had a decrease of $13.26 \pm 3.3 \%$ without significant differences among layers. Uncrated heads had higher FW/TW decreases, with this effect being more important under suboptimal conditions with a loss of $38.8 \pm 3.4 \%$ (Fig. 3J). 
Quality of lettuce packed in crates

308 Water movement took place in crated and uncrated heads and under both storage conditions.

309 The FW decrease may be due to water loss from evaporation when heads were exposed to a high

310 WVPD environment, as physiological responses to adverse environmental conditions, or to harvest

311 stress. Under these conditions, free water is bound within the cell causing a change in tissue water

312 status. Increases in $\mathrm{BW}$ and decreases in $\mathrm{FW}$ and $\mathrm{FW} / \mathrm{TW}$ were detected, and occurred in the tissue

313 in a saturated atmosphere.

\section{Mesophilic bacteria counts}

315 The most abundant microbial population in leafy vegetables is the mesophilic microflora (Watada et 316 al., 1996). Changes occurred in mesophilic bacteria counts (MBC) in crated or uncrated heads under 317 optimal and sub-optimal conditions (Fig. 3A,B). Heads from wooden crates exposed to optimal 318 conditions had increments of $0.45 \pm 0.15 \log$ in the upper layer, and similar, $1.10 \pm 0.16$ and $3191.05 \pm 0.20 \mathrm{log}$, values for heads in the middle and lower layers. Temperature within crates could be 320 responsible for these differences. Upper-layer heads had a more rapid temperature decline $321\left(6.9^{\circ} \mathrm{C} \cdot \mathrm{hr}^{-1}\right)$ during the first $2 \mathrm{hrs}$; for middle and lower layers it was 3.5 and $5.6^{\circ} \mathrm{C} \cdot \mathrm{hr}^{-1}$, respectively 322 (Fig. 2A). Crated heads exposed to sub-optimal conditions had MBC increments in all layers; 323 higher ones were detected in the middle and lower layers $(1.24 \pm 0.20 \log$ for both layers considered 324 together) than in the upper one $(0.98 \pm 0.14 \log )$.

325 The comparison between crated and uncrated heads exposed to optimal and sub-optimal 326 conditions, resulted in differences in MBC. In general, MBC were higher in crated than in uncrated 327 heads. The delay in temperature decrease in crated lettuce heads under optimal conditions (Fig. 2A) 328 favored mesophilic bacteria growth in middle and lower layers. For crated heads exposed to sub329 optimal conditions, high humidity and temperatures in crates (Fig. 2B) represented a more favorable 330 environment for mesophilic microorganisms compared with uncrated heads exposed to the same 331 conditions. Fonseca (2006), studying effects of environment humidity on microbial populations of 332 lettuce at harvest, found that high RH favored microorganism growth.

\section{Ascorbic acid content}

URL: http://mc.manuscriptcentral.com/wijv Email: vrusso-usda@lane-ag.org 
Quality of lettuce packed in crates

334 Numerous factors (principally temperature, salt and sugar concentrations, $\mathrm{pH}$, oxygen, enzymes,

335

336

337

338

339

340

341

342

343

344

345

346

347

348

349

350

351

352

353

354

355

356

357

358

among others) affect degradation of ascorbic acid (AA) (Davey et al., 2000; Lee and Kader, 2000).

It has been demonstrated that AA losses occur in some horticultural products in short periods immediately after harvest (Moreira et al., 2006). These reductions could be attributed to harvest stress (Lee and Kader, 2000; Moreira et al., 2006).

Changes occurred in AA in crated and uncrated lettuce heads exposed to different environmental conditions (Fig. 3C,D). Degradation of AA was not dependent on lettuce placement in crates; it was a function of environmental conditions to which the packed crate was exposed. In this way, heads from crates exposed to optimal conditions exhibited an average reduction of $9.93 \pm 4.96 \%$; for crated heads exposed to sub-optimal conditions the decline was doubled (18.99 $\pm 4.05 \%)$. Higher temperature and higher WVPD, generated in sub-optimal conditions, accelerated AA losses. The effect of temperature is well known (Kader, 2002): high temperature favors metabolic activity, and AA losses. It is generally accepted that leafy vegetables lose vitamins, especially AA, during postharvest (Lee and Kader, 2000). However, when vegetables are subjected to unfavorable environmental conditions, it is often questioned whether temperature or water loss are responsible for these nutritional losses (Moreira et al., 2006; Nunes et al., 1998).

Some argue that tissue water losses can increase AA losses due to oxidative processes (Kader, 2002; Paull, 1999).

By comparing results from crated (Fig. 4C) heads and uncrated heads (Fig. 4D), those in crates had smaller AA losses. This effect was more prominent when environmental condition were sub-optimal. Uncrated heads had an AA reduction of $54.52 \pm 2.80 \%$; crated heads had a lower AA reduction (18.99 $\pm 0.93 \%)$. The high relative humidity generated inside crates (Fig. 2B), allowed a higher AA retention than in uncrated heads. When the environment around lettuce heads had a high WVPD, nutritional losses increased, possibly due to tissue water loss.

\section{Chlorophyll content}

URL: http://mc.manuscriptcentral.com/wijv Email: vrusso-usda@lane-ag.org 
Quality of lettuce packed in crates

359 Leafy vegetables usually have reduced chlorophyll levels during storage. Chlorophyll degradation 360 is an expression of senescence in lettuce (León et al., 2007), rocket (Eruca sativa Mill.)

361 (Koukounaras et al., 2006), Swiss chard (Beta vulgaris L.) (Ferrante et al., 2004), and others.

362 Chlorophyll changes in crated and uncrated heads exposed to optimal and sub-optimal 363 conditions occurred (Fig. 3E,F). In crates exposed to optimal conditions, only heads from the upper 364 layer had a slight chlorophyll content reduction (4.71 $\pm 2.12 \%)$; heads from middle and lower layers 365 were not affected. Under sub-optimal conditions, chlorophyll decreases occurred in heads from the 366 middle and lower layers, which were similar (mean value of $6.85 \pm 2.0 \%$ ).

367 In general, more chlorophyll loss occurred in uncrated, than in crated lettuce heads. The 368 effect was more pronounced when conditions were sub-optimal, possibly due to the protective 369 effect inside crates. Chlorophyll loss in uncrated heads exposed to sub-optimal conditions reached $37050.52 \pm 4.5 \%$, while crated heads had chlorophyll retention of $90+\%$ in all layers. Uncrated lettuce 371 heads exposed to optimal conditions had retention of $87.50 \pm 3.2 \%$, and was almost $100 \%$ in crated 372 heads. The higher water movements in individual heads could be responsible for chlorophyll losses.

\section{Overall Visual Quality}

374 Lettuce sensory quality is made up of different components, including fresh appearance, color, 375 texture, and lack of browning, among others. It is accepted that storage time and environmental 376 conditions introduce certain degradation in lettuce appearance, mainly characterized by texture loss, 377 discoloration and browning (Kader, 2002). The impact of real commercial conditions during early 378 postharvest impacted overall visual quality (OVQ) of lettuce heads in crate layers and uncrated 379 heads (Fig. 3G, H). When conditions were optimal for lettuce handling, there was a OVQ reduction 380 of $0.7 \pm 0.1$ points and no differences between heads from different layers crates. Under sub-optimal 381 conditions, differences were found in OVQ from different layers, with higher OVQ decreases in 382 heads from upper layer (1.7 \pm 0.1$)$, followed by those from the lower layer $(1.4 \pm 0.1)$. Heads in the 383 middle layer had the smallest OVQ loss (1.0 \pm 0.2$)$. Two factors could be responsible for these 384 results. First, mechanical damage in heads due to packaging was higher in the lower layer due to 
Quality of lettuce packed in crates

385

386

387

compression from middle and upper layers, and in heads from the upper layer due to lateral compression due to placement of 9 plants in this layer. The other factor is relative humidity in the air space around heads. Only lettuce plants from the upper layer were exposed to an unsaturated atmosphere (Fig. 2B). Lettuce heads from middle and lower layers were exposed to a more saturated environment within the crate.

When OVQ between crated heads (Fig. 4G) and uncrated heads (Fig. 4H), was compared those in crates exposed to optimal conditions had a slightly higher decrease $(0.7 \pm 0.1)$ in OVQ than uncrated heads $(0.3 \pm 0.1)$. This could be attributed to mechanical damage generated during packaging as well as temperature inside the crate delaying achievement of the optimal temperature range (Fig. 2A). When environmental conditions were sub-optimal, the effect was opposite: with uncrated heads having a higher OVQ reduction (2.2 \pm 0.3$)$ compared to crated heads $(1.4 \pm 0.2)$. A more saturated atmosphere inside the crate (Fig. 2B), likely prevented water loss in tissues, could be responsible for this effect. For uncrated lettuce the OVQ reduction was due to wilting caused by dehydration (high WVPD of the environment); while in crated heads, the OVQ decrease was associated with mechanical damage of tissues. a different response in tissues from that in uncrated heads due to environmental conditions developed inside the crate and to the physical damage caused by the tightly packed heads.

When environmental conditions are the best recommended for butterhead lettuce $\left(0-2^{\circ} \mathrm{C}, 97-\right.$ $99 \% \mathrm{RH})$ the temperature profile developed inside crates slows down heat transfer. The recommended practice for buterhead lettuce, widely used in many European countries, is temperature reduction by vacuum cooling, before storage under optimal conditions. Use of maintenance chambers to achieve the temperature reduction is inefficient compared to vacuum cooling. The cold temperature is achieved between 5 to $16 \mathrm{hrs}$ depending on placement of product within crates, and this cooling delay negatively impacts quality indices compared to uncrated heads. Besides the temperature effect, the wooden crate system causes mechanical damage in the tissue 
Quality of lettuce packed in crates

411 due to pressure exerted on lettuce heads placed in wooden crates. When conditions are the best

412 recommended for the handling of butterhead lettuce respiration heat, and head placement inside

413 crates generate a delay in lowering the temperature with a direct effect in lettuce quality indices.

414 When the environmental conditions are sub-optimal, respiration and transpiration of lettuce

415 in crates permits development of a saturated atmosphere. Proximity of heads constitutes a physical

416 barrier against low RH. However, crated lettuce heads, exposed to sub-optimal conditions, had

417 bigger quality losses than crated heads exposed to optimal conditions.

418 It is important to highlight the economic losses taking place during the first 24 hours after 419 harvest. Weight losses results in economical loss. There is a need to improve and optimize 420 handling of fresh produce during marketing. Upgraded technology should be implemented to 421 maintain high produce quality achieved by producers as long as possible and ensure delivery of 422 high quality products to consumers.

\section{REFERENCES}

424 Agüero, M.V., A.G. Ponce, A. Bevilacqua, and S.I. Roura. 2011a. Postharvest quality losses of 425 butter lettuce as affected by leaf age and temperature. Fresh Produce 5(1): 20-25.

426 Agüero, M.V., M.R. Moreira, G. Goñi, and S.I. Roura. 2011b. Abusive isothermal conditions 427 during first hours after harvest affect butterhead lettuce water status. J. Food Process. Pres. $428 \quad 35(4): 501-508$.

429 Agüero, M.V., A.G. Ponce, M.R. Moreira, and S.I. Roura. 2011c. Lettuce quality loss under 430 conditions that favor the wilting phenomenon. Posthar. Biol. Technol. 59: 124-131.

431 Agüero, M.V., M.V. Barg, A. Yommi, A. Camelo, and S.I. Roura. 2008. postharvest changes in 432 water status and chlorophyll content of lettuce (Lactuca sativa L.) and their relationship 433 with overall visual quality. J. Food Sci. 73(1): 47-55.

434 Ahumada, O. and J.R. Villalobos. 2009. Application of planning models in the agri-food supply 435 chain: A review. Eur. J. Oper. Res. 195: 1-20. 
Quality of lettuce packed in crates

436 Burdon, J. and C. Clark. 2001. Effect of postharvest water loss on "Hayward" kiwifruit water status. Postharvest Biol. Technol. 22: 215-225.

Chandra, D., T. Matsui, H. Suzuki, and Y. Kosugi. 2008. Changes in some physio-biochemical characteristics in lettuce during storage at low temperature. J. Biol. Sci. 8(2): 398-403.

440 Davey, M.W., M. Van Montagu, D. Inzé, M. Sanmartin, A. Kanellis, N. Smirnoff, I.J.J. Benzie, J.J. Strain, D. Favell, and J. Fletcher. 2000. Plant L-ascorbic acid: chemistry, function, metabolism, bioavailability and effects of processing. J. Sci. Food Agric. 80: 825-860.

Fonseca, J.M. 2006. Postharvest quality and microbial population of head lettuce as affected by moisture at harvest. J. Food Sci. 71(2): M45-M49.

Guevara-Arauza, J.C., E.M Yahia, L. Cedeño, and L.M.M Tijskens. 2006. Modeling the effects of temperature and relative humidity on gas exchange of prickly pear cactus (Opuntia spp.) stems. Lebensm. Wiss. Technol. 39: 796-805.

He, S.Y. and Y.F. Li. 2008. Experimental study and process parameters analysis on the vacuum cooling of iceberg lettuce. Energ. Convers. Manage. 49:2720-2726.

Hertog, M.L.A.T.M., R. Ben-Arie, E. Róth, and B.M Nicolaï. 2004. Humidity and temperature effects on invasive and non-invasive firmness measures. Posthar. Biol. Technol. 22: 79-91.

Kader, A.A. 2002. Postharvest biology and technology: An overview, pp. 39-47. In: A.A. Kader (ed.). Postharvest technology of horticultural crops. University of California, Agriculture

Kuehl, R.O. 2001. Diseño de experimentos, 2nd ed. Thompson Learning International, México DF. and tissue browning of rambutan fruit. Sci. Horticult. 66: 201-208. 
Quality of lettuce packed in crates

462 Lee, S.K. and A.A. Kader. 2000. Preharvest and postharvest factors influencing vitamin C content of horticultural crops. Postharvest Biol. Technol. 20(3): 207-220.

464 León, A., D. Frezza, and A. Chiesa. 2007. Evolución del color en lechuga (Lactuca sativa L.) mantecosa mínimamente procesada: Efecto del troceado y la inmersión en cloruro de calcio. V Congreso Iberoamericano de Tecnología Postcosecha y Agroexportaciones. (Evolution of color in minimally processed butterhead lettuce (Lactuca sativa L.): Effect of cut and immersion in calcium chloride. V Iberoamerican Congress of postharvest technology and agroexportations) 5: 666-675.

Mahajan, P.V., F.A.R. Oliveira, and I. Macedo. 2008. Effect of temperature and humidity on the transpiration rate of the whole mushrooms. J. Food Eng. 84: 281-288.

Martínez-Romero, D., M. Serrano, G. Bailén, F. Guillén, P.J. Zapata, J.M. Valverde, S. Castillo, M. Fuentes, and D. Valero. 2008. The use of natural fungicide as an alternative to preharvest synthetic fungicide treatments to control lettuce deterioration during postharvest storage. Postharvest Biol. Technol. 47: 54-60.

Martínez, J.A. and F. Artes. 1999. Effect of packaging treatments and vacuum-cooling on quality of winter harvested iceberg lettuce. Food Res. Int. 32: 621-627.

Mc Donald, K. and D.W. Sun. 2000. Vacuum cooling technology for the food processing industry: a review. J. Food Eng. 45: 55-65.

Mondino, M.C., J. Ferratto, I. Firpo, R. Rotondo, M. Ortiz Mackinson, R. Grasso, P. Calani, and A. Longo. 2007. Pérdidas poscosecha de lechuga en la región de Rosario, Argentina. Horticult. Argentina 26(60): 17-24.

Moreira, M.R., A.G. Ponce, C.E. del Valle, and S.I. Roura. 2005. Inhibitory parameters of essential oils to reduce a foodborne pathogen. Lebensm. Wiss. Technol. 38(5): 565-570.

Moreira, M.R., A.G. Ponce, C.E. del Valle, R. Ansorena, and S.I. Roura. 2006. Effects of abusive temperatures on the postharvest quality of lettuce leaves: ascorbic acid loss and microbial growth. J. App. Hort. 8(2): 109-113.

URL: http://mc.manuscriptcentral.com/wijv Email: vrusso-usda@lane-ag.org 
Quality of lettuce packed in crates

488

489

490

491

492

493

494

495

496

497

498

499

500

501

502

503

504

505

506

507

508

509

510

511

Ngure, J.W., J.N. Aguyoh, and L. Gaoquiong. 2009. Interactive effects of packaging and storage temperatures on the shelf-life of okra. J. Agric. Biol. Sci. 4(3): 44-49.

Nguyen, T.A., P. Verboven, A. Schenk, and B.M. Nicolaï. 2007. Prediction of water loss from pears (Pyrus communis cv. Conference) during controlled atmosphere storage as affected by relative humidity. J. Food Eng. 83: 149-155.

Nunes, M.C.N., J.K. Brecht, A. Morais, and S.A. Sargent. 1998. Controlling temperature and water loss to maintain ascorbic acid levels in strawberries during postharvest handling. J. Food Sci. 63: 1033-1036.

Nunes, M.C.N., J.P. Emond, M. Rauth, S. Dea, and K.V. Chau. 2009. Environmental conditions encountered during typical consumer retail display affect fruit and vegetable quality and waste. Postharvest Biol. Technol. 51: 232-241.

Ozturk, H.M. and H.K. Ozturk. 2009. Effect of pressure on the vacuum cooling of iceberg lettuce. Int. J. Refrig. 32: 402-410.

Paull, R.E. 1999. Effect of temperature and relative humidity on fresh commodity quality. Postharvest Biol. Technol. 15: 263-277.

Ponce, A., S. Roura, C. del Valle, and R. Fritz. 2002. Characterization of native microbial population of Swiss chard (Beta vulgaris, type cicla). Lebensm. Wiss. Technol. 35: 331-337.

Roura, S.I., M.R. Moreira, G. Crapiste, and C.E. del Valle. 2001. Biochemical characterization of two pepper varieties in green and red maturation stages. Italian J. Food Sci. 4(13): 391-397.

Viacava, G.E., S.I. Roura, and M.V. Agüero. 2011. Improvement of water status methodology for leafy vegetables reduces time consuming, skilled labor and laboratory resources. Food Anal. Method. 4(3): 307-312.

Watada, A.E., N.K. Ko, and D.A. Minott. 1996. Factors affecting quality of fresh-cut horticultural products. Posthar. Biol. Technol. 9: 115-125. 


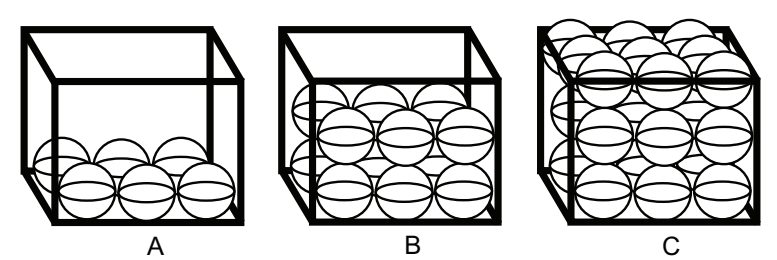

4

5 Figure 1. Schematic representation of crate assembly with six lettuce heads in the lower layer (A), 6 six lettuce heads in the middle layer (B), and nine lettuce heads in the upper layer (C). 7 

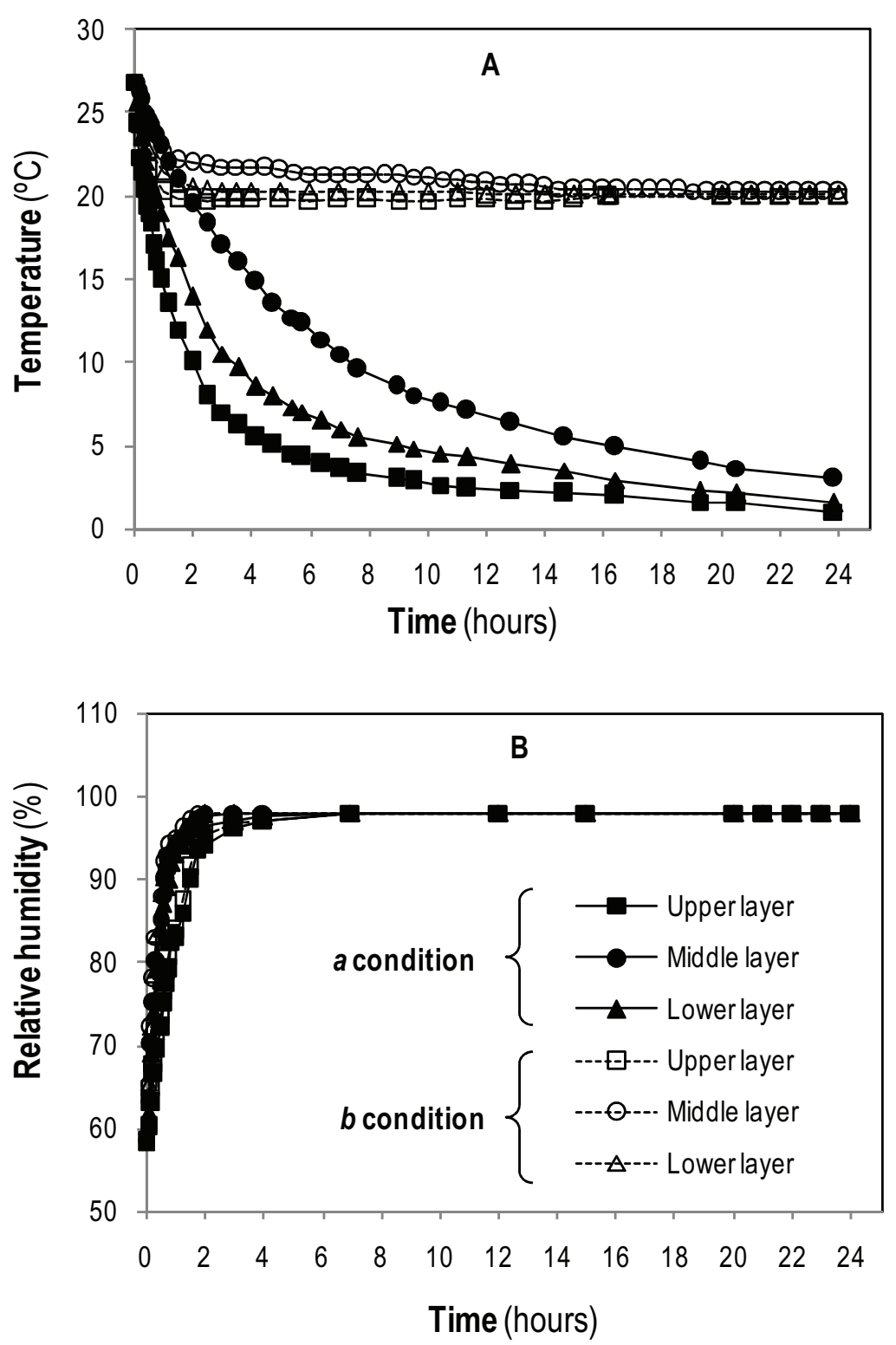

1

2 Figure 2. Changes in temperature (A) and relative humidity (B) in layers of heads in wooden crates 3 exposed to: $0-2^{\circ} \mathrm{C}$ and $97-99 \% \mathrm{RH}$ (whole lines) or $20-22^{\circ} \mathrm{C}$ and $60-62 \% \mathrm{RH}$ (tacked lines). 4 

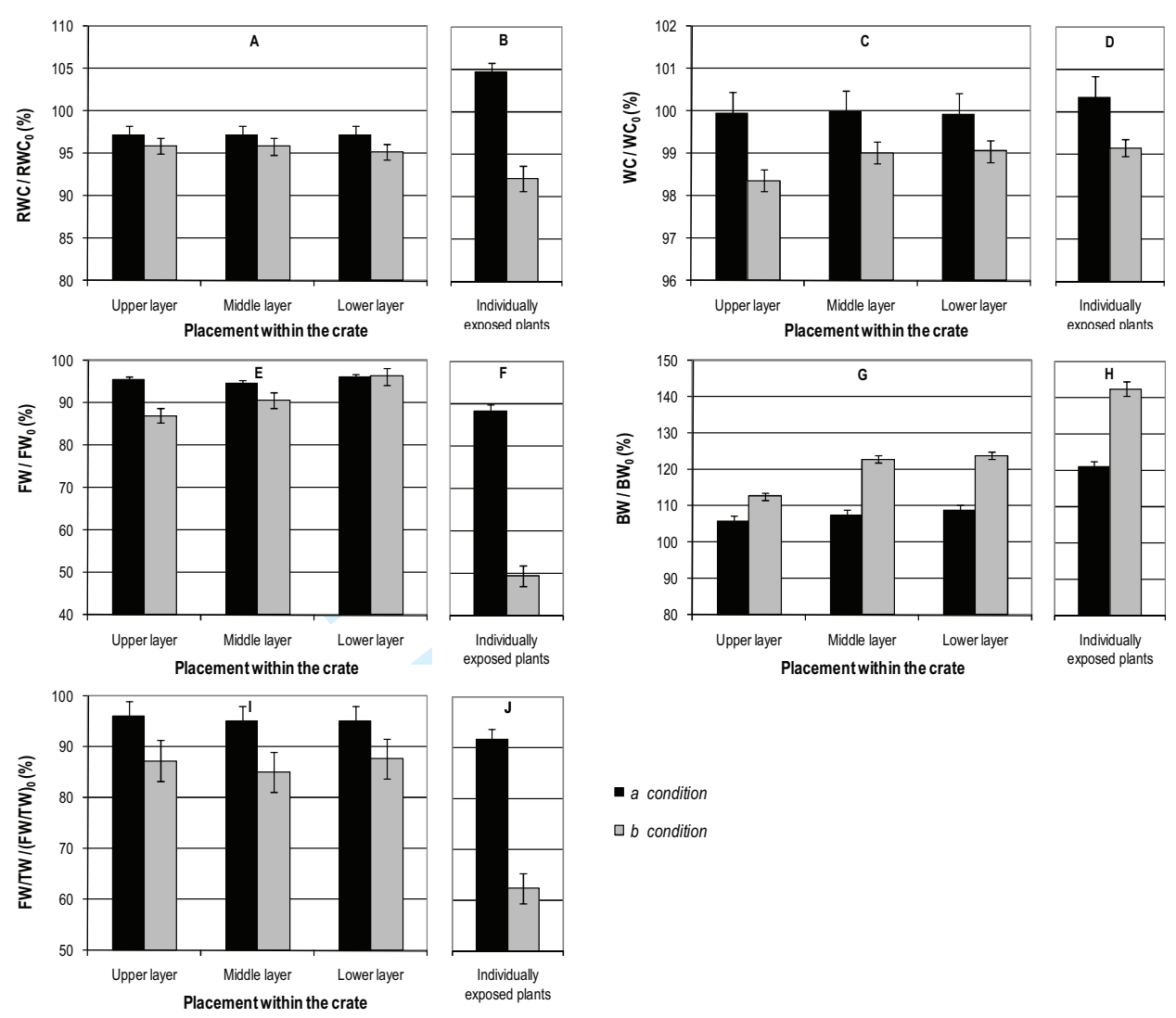

- a condition

$\square b$ condition

2 Figure 3. Changes in water status indices (RWC, WC, FW, BW and FW/TW) in lettuce heads in 3 layers in wooden crates or uncrated heads exposed for $24 \mathrm{hrs}$ to $0-2^{\circ} \mathrm{C}, 97-99 \% \mathrm{RH}(a)$ or $20-22^{\circ} \mathrm{C}$, $4 \quad 60-62 \% \mathrm{RH}(b)$ conditions. 

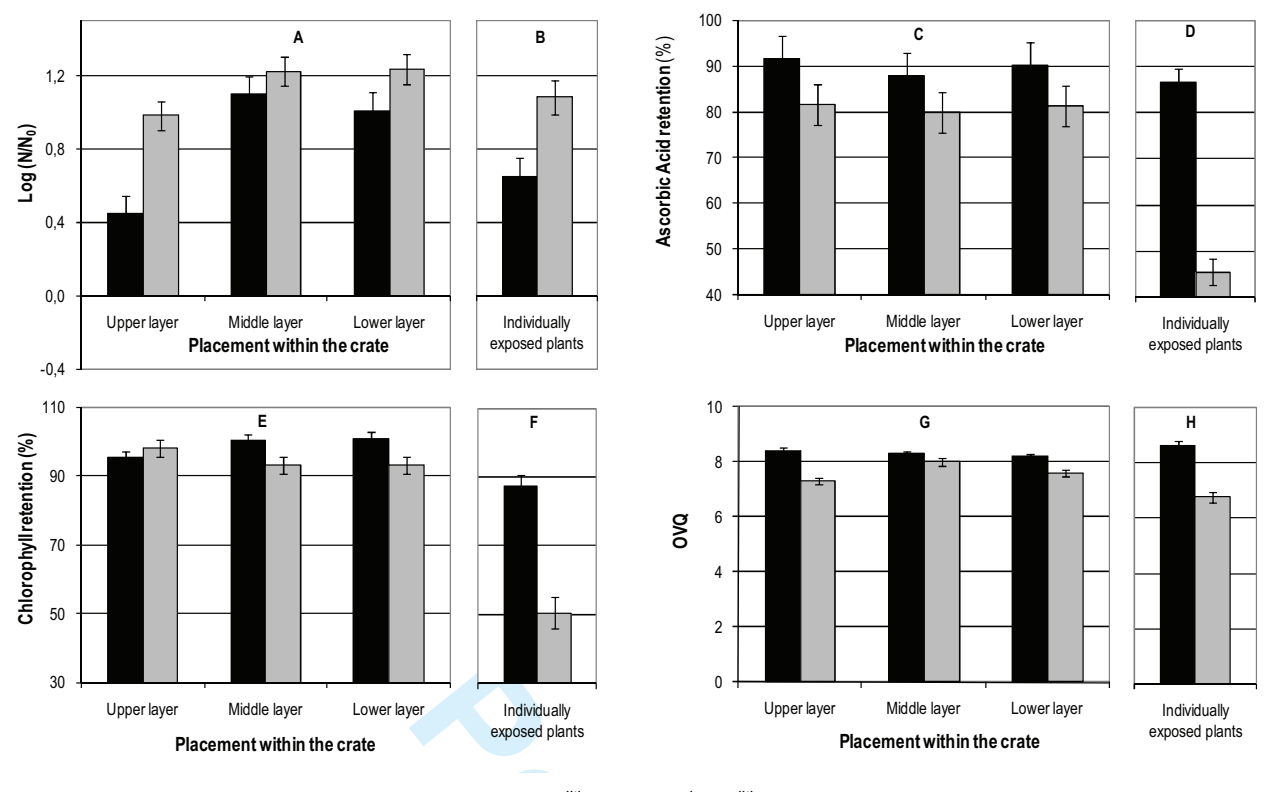

1

$\square$ b condition

2 Figure 4. Changes in quality indices (mesophilic bacteria count, chlorophyll content, ascorbic acid 3 content and OVQ) in lettuce heads placed in layers within wooden crates or uncrated heads stored 4 for $24 \mathrm{hrs}$ to $0-2^{\circ} \mathrm{C}, 97-99 \% \mathrm{RH}(a)$ or $20-22^{\circ} \mathrm{C}, 60-62 \% \mathrm{RH}(b)$ conditions. 
Table 1. Analysis of variance for weight loss (WL\%) and weight loss after waste disposal $\left(\mathrm{WL}_{\mathrm{d}} \%\right.$ ) occurring after exposure of lettuce heads packed in different layers in wooden crates to $0-2^{\circ} \mathrm{C}, 97-99 \% \mathrm{RH}$ or $20-22^{\circ} \mathrm{C}, 60-62 \% \mathrm{RH}$ for $24 \mathrm{hrs}$ and layer.

\begin{tabular}{|c|c|c|c|c|c|}
\hline Source of variation & $d f$ & Sum of squares & Mean squares & $F$ & $p$ \\
\hline & \multicolumn{5}{|c|}{$W L$} \\
\hline Cond & 1 & 1057.8 & 1057.8 & 4991411 & $<0.0001$ \\
\hline Layer & 2 & 100.8 & 50.4 & 237944 & $<0.0001$ \\
\hline Cond $\times$ Layer & 2 & 87.1 & 43.5 & 205458 & $<0.0001$ \\
\hline Error & 246 & 0.05 & 0.0002 & & \\
\hline \multirow[t]{2}{*}{ Total } & 251 & 1245.8 & & & \\
\hline & \multicolumn{5}{|c|}{$W L_{d}$} \\
\hline Cond & 1 & 40286 & 40286 & $1.9 \mathrm{E} 8$ & $<0.0001$ \\
\hline Layer & 2 & 576 & 288 & 1359012 & $<0.0001$ \\
\hline Cond $\times$ Layer & 2 & 180.2 & 90.1 & 425249 & $<0.0001$ \\
\hline Error & 246 & 0.05 & 0.0002 & & \\
\hline Total & 251 & 41042 & & & \\
\hline
\end{tabular}


Table 2. Interaction of storage condition and layer on weight loss (WL\%) and weight loss after waste disposal $\left(\mathrm{WL}_{\mathrm{d}} \%\right)$ in lettuce heads in layers in wooden crates exposed | for $24 \mathrm{hrs}$ to $0-2{ }^{\circ} \mathrm{C}, 97-99 \% \mathrm{RH}$ (Optimal) or $20-22^{\circ} \mathrm{C}, 60-62 \% \mathrm{RH}$ (Sub-optimal) conditions.

\begin{tabular}{lccc}
\hline Storage condition & Layer & $\mathrm{WL}^{\mathrm{a}}{ }^{\mathrm{a}}$ & $\mathrm{WL}_{\mathrm{d}} \%$ \\
\hline Optimal & Upper & 2.43 & 9.20 \\
& Middle & $2.11 \mathrm{~ns}$ & $7.72 \mathrm{~ns}$ \\
& Lower & $1.47^{* *}$ & $12.23{ }^{* *}$ \\
Sub-optimal & Upper & 7.09 & 36.35 \\
& Middle & $4.37^{* *}$ & $32.28 \mathrm{~ns}$ \\
& Lower & $6.56^{* *}$ & $35.45 \mathrm{~ns}$
\end{tabular}

ns, ** non-significant or significant at $\mathrm{P} \leq 0.01$, Least Squares Means analysis.

${ }^{\mathrm{a}} \mathrm{WL} \%=$ Weight loss percent; $\mathrm{WL}_{\mathrm{d}} \%=$ Weight loss after waste disposal percent.

URL: http://mc.manuscriptcentral.com/wijv Email: vrusso-usda@lane-ag.org 
Table 3. Analysis of variance for weight loss (WL\%) and weight loss after waste disposal $\left(\mathrm{WL}_{\mathrm{d}} \%\right)$ produced after exposure of crated or uncrated lettuce heads to $0-2^{\circ} \mathrm{C}$, 97-99\% RH (optimal) or $20-22^{\circ} \mathrm{C}, 60-62 \% \mathrm{RH}$ (sub-optimal) conditions for $24 \mathrm{hrs}$.

\begin{tabular}{|c|c|c|c|c|c|}
\hline Source of variation & $d F$ & Sum of squares & Mean squares & $F$ & $p$ \\
\hline & \multicolumn{5}{|c|}{$W L$} \\
\hline Cond & 1 & 1361.7 & 1361.7 & 191178 & $<0.0001$ \\
\hline Pack & 1 & 56.2 & 56.2 & 7897 & $<0.0001$ \\
\hline Cond $\times$ Pack & 1 & 176.7 & 176.7 & 24815 & $<0.0001$ \\
\hline Error & 44 & 0.31 & 0.007 & & \\
\hline \multirow[t]{3}{*}{ Total } & 47 & 1595 & & & \\
\hline & \multicolumn{5}{|c|}{$W L_{d}$} \\
\hline & 1 & 14868.5 & 14868.5 & 1380196 & $<0.0001$ \\
\hline Pack & 1 & 69.8 & 69.8 & 6479.9 & $<0.0001$ \\
\hline Cond $\times$ Pack & 1 & 422.3 & 422.3 & 39201.1 & $<0.0001$ \\
\hline Error & 44 & 0.47 & 0.01 & & \\
\hline
\end{tabular}


Table 4. Interaction of storage condition and packaging on weight loss (WL\%) and weight loss after waste disposal $\left(\mathrm{WL}_{\mathrm{d}} \%\right)$ in crated and uncrated lettuce heads exposed for $24 \mathrm{hrs}$ to $0-2^{\circ} \mathrm{C}, 97-99 \% \mathrm{RH}$ (Optimal) or $20-22^{\circ} \mathrm{C}, 60-62 \% \mathrm{RH}$ (Sub-optimal) conditions.

Storage

\begin{tabular}{llll} 
condition & Packaging & WL\% & WL $_{d} \%$ \\
\hline Optimal & Crated & 2.00 & 9.72 \\
& Uncrated & $0.00^{* *}$ & $0.00^{* *}$ \\
Sub-optimal & Crated & 6.01 & 34.69 \\
& Uncrated & $12.92^{* *}$ & $38.76 \mathrm{~ns}$
\end{tabular}

$\mathrm{ns},{ }^{* *}$ non-significant or significant at $\mathrm{P}<0.01$, Least Squares Means analysis. 